\title{
Rapid Coupling of Calcium Release to Depolarization in Limulus polyphemus Ventral Photoreceptors as Revealed by Microphotolysis and Confocal Microscopy
}

\author{
Kyrill Ukhanov and Richard Payne \\ Department of Zoology, University of Maryland, College Park, Maryland 20742
}

\begin{abstract}
Microphotolysis and confocal microscopy were used to investigate the timing of calcium release and of the electrical response in Limulus polyphemus ventral photoreceptors. The fluorescent dyes Fluo-3 and Calcium Green-5N were used to monitor local $\mathrm{Ca}^{2+}$ elevations. Photolysis of caged inositol trisphosphate $\left(\operatorname{InsP}_{3}\right)$ close to the plasma membrane of the light-sensitive rhabdomeral ( $\mathrm{R}$-) lobe resulted in $\mathrm{Ca}^{2+}$ elevation within 10-20 msec, 20-45 msec before the physiological response to light normally would be detected. Inward ionic current flow and depolarization followed InsP $_{3}$-induced calcium release within $2.5 \pm 3.3 \mathrm{msec}$. Voltage-clamping the cells and removal of extracellular $\mathrm{Ca}^{2+}$ did not affect the timing of the $\mathrm{Ca}^{2+}$ elevation that followed the photolysis of caged InsP $\mathrm{P}_{3}$ or its relationship to the electrical response. In contrast to the physiological response to light, which only released calcium within
\end{abstract}

the R-lobe, photolysis of $\operatorname{InsP}_{3}$ elevated $\mathrm{Ca}_{\mathrm{i}}$ in both lobes, although with much greater effect in the R-lobe, as compared with the bulk of the A-lobe, suggesting the presence of InsP ${ }_{3}$ sensitive calcium stores in both lobes. Photolysis of caged calcium [o-nitrophenyl EGTA (NPE)] at the edge of the R-lobe activated an inward ionic current within $1.8 \pm 0.7 \mathrm{msec}$. This NPE-induced current reversed at a membrane potential of $10 \pm$ $6 \mathrm{mV}$ in the range typical of that of the light-activated current under physiological conditions. Calcium release, therefore, activates an inward current rapidly enough to contribute to the electrical response to light.

Key words: phototransduction; Limulus polyphemus; photoreceptor; nitrophenyl EGTA (NPE); caged Ins $P_{3}$; confocal microscopy
The light response in invertebrate photoreceptors is thought to be mediated by the ubiquitous phosphoinositide-signaling (PI) pathway (Bloomquist et al., 1988; Hardie and Minke, 1995; Ranganathan et al., 1995). The major known products of the PI pathway are inositol 1,4,5 trisphosphate $\left(\mathrm{InsP}_{3}\right)$, which releases stored calcium ions, and diacylglycerol (Berridge, 1993). However, there is no clear understanding of how the products of the PI pathway can be linked to the opening of the ion channels that depolarize the membrane potential of the photoreceptor. For the ventral photoreceptors of the horseshoe crab (Limulus polyphemus), intracellular pressure injections of $\mathrm{InsP}_{3}$ or $\mathrm{Ca}^{2+}$ ions activate, in darkness, an inward current having a reversal potential $\left(E_{\mathrm{rev}}\right)$ similar to that of the light-activated current (Brown et al., 1984; Fein et al., 1984). The injections also subsequently desensitize the light response. Therefore, elevation of the cytosolic $\mathrm{Ca}^{2+}$ ion concentration $\left(\mathrm{Ca}_{\mathrm{i}}\right)$ is thought to play a role in both excitation and adaptation of Limulus photoreceptors (Frank and Fein, 1991; Nagy, 1991; Shin et al., 1993; Contzen et al., 1995). However, it has not been possible so far to verify that released calcium can activate ion channels sufficiently rapidly to contribute to the generation of inward current during the light response. In excised patches of light-sensitive membrane, cyclic guanosine monophos-

\footnotetext{
Received Sept. 3, 1996; revised Dec. 20, 1996; accepted Dec. 23, 1996.

This work was supported by National Institutes of Health Grant EY-07743. We thank Dr. Ian Mather of the Department of Animal Sciences, University of Maryland, College Park, for the use of the confocal microscope and Drs. Roger Hardie and Mark Gray-Keller for their comments.

Correspondence should be addressed to Dr. Richard Payne, Department of Zoology, University of Maryland, College Park, MD 20742.

Dr. Ukhanov's present address: Institut fuer Zellphysiologie, Universitaet Potsdam, Lennestrasse 7a, D-14471 Potsdam, Germany.

Copyright (C) 1997 Society for Neuroscience $0270-6474 / 97 / 171701-09 \$ 05.00 / 0$
}

phate (cGMP), but not calcium ions, activates ion channels (Bacigalupo et al., 1991). Calcium-activated production of cGMP has, therefore, been proposed to couple the elevation of $\mathrm{Ca}_{\mathrm{i}}$ to the activation of ion channels (Shin et al., 1993). The proposal of this additional step raises further doubts that calcium can act rapidly enough. Therefore, the time taken for released calcium to activate an inward current is clearly critical for determining the role of light-induced calcium release in mediating the electrical response to light. To investigate the timing of the response to released calcium ions, we have used fluorescent calcium-sensitive dyes and photolysis of caged $\mathrm{InsP}_{3}$ and nitrophenyl EGTA (NPE) to create and measure spatially localized calcium transients with a millisecond time resolution (Walker et al., 1989; Ellis-Davies and Kaplan, 1994).

\section{MATERIALS AND METHODS}

Ventral optic nerves were dissected as described by Millecchia and Mauro (1969) and placed in artificial seawater (ASW) containing (in $\mathrm{mM}$ ): $435 \mathrm{NaCl}, 10 \mathrm{KCl}, 20 \mathrm{MgCl}_{2}, 25 \mathrm{MgSO}_{4}, 10 \mathrm{CaCl}_{2}$, and $10 \mathrm{HEPES}$, $\mathrm{pH}$ 7.0. For some experiments the preparation was kept on ice in ASW containing $40 \mathrm{~mm}$ hydroxylamine for 15 min under bright white light (Faddis and Brown, 1992). After treatment with 1\% Pronase, ventral photoreceptor cells were impaled with a glass micropipette. A solution containing 10-25 mM GDP- $\beta$ S [guanosine-5'-O-(2-thiodiphosphate); Calbiochem, La Jolla, CA], 1 mm Fluo-3 or Calcium Green-5N (Molecular Probes, Eugene, OR), $10 \mathrm{~mm}$ caged $\mathrm{InsP}_{3}$ (Calbiochem), $100 \mathrm{~mm}$ $\mathrm{K}$-aspartate, and $10 \mathrm{~mm}$ HEPES, $\mathrm{pH}$ 7.0, was pressure-injected from the micropipette into the cells. Approximately 50-100 injections of 1-10 pl were delivered before the beginning of the experiment. Caged ATP (10 $\mathrm{mm}$; Calbiochem) replaced caged $\mathrm{InsP}_{3}$ in the injection solution for control experiments.

For experiments using caged calcium, $40 \mathrm{~mm}$ NPE (o-nitrophenyl EGTA hexapotassium salt; Molecular Probes) mixed with $32 \mathrm{~mm} \mathrm{CaCl}_{2}$ replaced caged $\mathrm{InsP}_{3}$ in the micropipette solution. A $0.8 \mathrm{Ca}-\mathrm{NPE}$ mixture 
should yield a $\mathrm{Ca}^{2+}$ concentration of $\sim 1 \mu \mathrm{M}$ (Ellis-Davies and Kaplan, 1994). After multiple UV flashes, $\mathrm{Ca}_{\mathrm{i}}$ was increased irreversibly in some cells, presumably because of the cumulative shift in the Ca:NPE ratio. This sustained elevation of $\mathrm{Ca}_{\mathrm{i}}$ was associated in some cells with a sustained inward current (Shin et al., 1993).

Ventral nerves were viewed with a Zeiss LSM 410 laser-scanning confocal microscope equipped with a $488 \mathrm{~nm}$ argon laser (Uniphase) focused through a Zeiss Neofluor $40 \times / 0.75$ objective lens (for details, see Ukhanov and Payne, 1995). A 351/364 nm ion argon laser (Innova Technologies) also was focused through the same objective lens and was used to photolyze caged compounds. The UV laser intensity was attenuated by neutral density filters and is expressed here by an arbitrary relative scale. High-speed shutters (Uniblitz model 26L, Vincent Associates, Rochester, NY) were placed in the path of the laser beams to control the timing and duration of flashes. A procedure similar to that described by Wang and Augustine (1996) was used to check that the focus and position of the UV spot were coaxial with the $488 \mathrm{~nm}$ laser beam. Briefly, photobleaching of a thin polysterene film stained with Nile Red was used to determine the position of the focused spots created by the 488 $\mathrm{nm}$ and UV lasers.

For line scans, the laser beam swept every 4 msec across the cell, each scan containing 512 pixels. In all, 512 successive scans were stacked to create a raw image of fluorescence that represented $2.048 \mathrm{sec}$ of recording time. Changes of $\mathrm{Ca}_{\mathrm{i}}$ on illumination of the photoreceptors were displayed as a ratio of fluorescence relative to the fluorescence, $F_{\mathrm{o}}$, recorded during the latent period of the response. National Institutes of Health IMAGE software (written by Wayne Rasband at National Institutes of Health and available via anonymous ftp from zippy.nimh.nih.gov) was used for off-line image processing, including smoothing and ratio calculations. Smoothing reduced the spatial resolution of line scans to 4 $\mu \mathrm{m}$. By photobleaching Nile Red-stained polystyrene film, we also determined the uniformity of illumination during laser beam scans. We found that the intensity of the laser beams varied by $<30 \%$ over the first 412 pixels of the scan. However, the beam intensity increased fourfold over the final 100 pixels because of a slowing of the movement of the beam toward the end of each scan. To avoid artifacts because of increased photolysis in this region of the scan, we deleted from our analysis the 100 pixels at the right-hand side of every line in the stack.

Membrane voltage or ionic current were recorded with an Axoclamp-2A amplifier (Axon Instruments, Foster City, CA) and digitally sampled at a rate of at least $1 \mathrm{kHz}$. For current recording and measuring of the $E_{\mathrm{rev}}$ under two-electrode voltage clamp, the cells were impaled with a second micropipette filled with $3 \mathrm{M} \mathrm{KCl}$ (resistance $<10 \mathrm{M} \Omega$ ).

\section{RESULTS}

\section{Use of GDP- $\beta$ S and hydroxylamine to prolong response latency}

We previously have used steps of light delivered by the $488 \mathrm{~nm}$ laser of our confocal microscope to excite ventral photoreceptors and simultaneously to monitor $\mathrm{Ca}_{\mathrm{i}}$ (Ukhanov and Payne, 1995). To release caged compounds, we delivered a flash from a $364 \mathrm{~nm}$ laser at the onset of the $488 \mathrm{~nm}$ step, both lasers being focused onto the same point (see Materials and Methods). The application of caged compounds to functioning photoreceptor cells presents a challenge, because rhodopsin absorbs the UV light required for photolysis. This would be expected to accelerate calcium release and the electrical response through the normal physiological pathway. It is, therefore, important to reduce the sensitivity of the physiological pathway as much as possible. In the case of Limulus ventral photoreceptors, the physiological response to the intense laser light delivered by our confocal microscope is delayed by a latent period of $\sim 20 \mathrm{msec}$ (Ukhanov and Payne, 1995). To reduce the gain of phototransduction and to increase the latent period even further, we followed the protocol of Faddis and Brown (1992), treating the cells with hydroxylamine and injecting them with GDP- $\beta$ S. By bleaching rhodopsin (Hubbard and Wald, 1960) and inhibiting GTP-binding proteins (Fein, 1986), respectively, these agents slow excitation of the cells by light without affecting the response to injected $\mathrm{InsP}_{3}$ (Faddis and
Brown, 1992). As a result, the latency of the normal physiological response to both the $488 \mathrm{~nm}$ laser and the flash from the UV laser is prolonged to $30-50 \mathrm{msec}$ (Payne and Ukhanov, 1996). This latency enabled us to observe the effects of the release of caged compounds, which photolyze within 1-3 msec, before any physiological response caused by the activation of rhodopsin is detectable.

\section{Photolysis of caged Ins $\mathrm{P}_{3}$ rapidly elevates $\mathrm{Ca}_{\mathrm{i}}$ in ventral photoreceptors}

Ventral photoreceptors were injected with GDP- $\beta$ S, caged $\operatorname{InsP}_{3}$, and the calcium indicator dye Fluo-3 and were viewed with a laser- scanning confocal microscope. After orientation of the laser beam, a line scan was performed in a plane that passed through the interior of the light-sensitive rhabdomeral (R-) lobe of the photoreceptor, the insensitive arhabdomeral (A-) lobe (Calman and Chamberlain, 1982), and the axon (Fig. $1 A$ ). The $488 \mathrm{~nm}$ laser used for this line scan excited the cell through the normal physiological mechanism without photolyzing the cage and simultaneously elicited fluorescence from Fluo-3 so as to monitor accompanying changes in $\mathrm{Ca}_{\mathrm{i}}$. After a latent period of $40 \mathrm{msec}$, the elevation of $\mathrm{Ca}_{\mathrm{i}}$ began at the extreme edge of the R-lobe beneath the photoreceptive microvillar membrane (Ukhanov and Payne, 1995) and then spread over the next $400 \mathrm{msec}$ toward the boundary between the R-lobe and the light-insensitive A-lobe (Fig. $1 B$, upper frame). The elevation of $\mathrm{Ca}_{\mathrm{i}}$ barely penetrated the A-lobe. In five cells, Fluo-3 fluorescence recorded during illumination by the $488 \mathrm{~nm}$ laser within $10 \mu \mathrm{m}$ of the edge of the R-lobe rose to a peak of $3.7 \pm 0.8$ times its initial level (mean \pm SD). At $70 \mu \mathrm{m}$ from the edge of the R-lobe, the fluorescence remained at $1.1 \pm$ 0.11 times its initial level over the same time period. A $10 \mathrm{msec}$ flash from a UV laser then was superimposed at the beginning of a second $488 \mathrm{~nm}$ scan. This flash initiated fast cleavage of caged InsP $\mathrm{P}_{3}$, with consequent elevation of $\mathrm{Ca}_{\mathrm{i}}$ within $30 \mathrm{msec}$ along the entire length of the scanned line within the R-lobe (Fig. $1 B$, lower frame). The elevation of $\mathrm{Ca}_{\mathrm{i}}$ along the scanned line in the A-lobe was much less than that in the R-lobe, with the exception of a region close to the axon. For the same five cells, the peak Fluo-3 fluorescence after the UV flash recorded within $10 \mu \mathrm{m}$ of the edge of the R-lobe was $4.0 \pm 0.7$ times its initial level (mean $\pm \mathrm{SD})$. At $70 \mu \mathrm{m}$ from the edge of the R-lobe, the peak fluorescence was $1.6 \pm 0.6$ times its initial level.

To verify that most of the $\mathrm{Ca}_{\mathrm{i}}$ rise comes from the release of internal calcium stores, we removed $\mathrm{Ca}^{2+}$ from the ASW bathing another ventral nerve. The nerve was kept in darkness for $30 \mathrm{~min}$ in ASW containing $1 \mathrm{~mm}$ EGTA instead of $10 \mathrm{~mm} \mathrm{Ca}^{2+}$. As expected from previous work (Lisman, 1976; Payne and Flores, 1992), removal of extracellular $\mathrm{Ca}^{2+}$ increased the latent period of the physiological response to the $488 \mathrm{~nm}$ scan (Fig. 1C, upper frame) to $230 \mathrm{msec}$. Nevertheless, a brief UV flash elicited as rapid a response to photolysis of $\mathrm{InsP}_{3}$ along the entire scanned line as for cells bathed in $10 \mathrm{mM} \mathrm{Ca}^{2+}$ (Fig. 1C, lower frame). These results might be explained if prolonged exposure of the cell to zero extracellular $\mathrm{Ca}^{2+}$ and the accompanying reduction of resting levels of $\mathrm{Ca}_{\mathrm{i}}$ (Levy and Fein, 1985; Ukhanov et al., 1995) resulted in a slowing of light-induced phospholipase-C activity (Rack et al., 1994; Mitchell et al., 1995).

\section{Rapid coupling of Ins $\mathrm{P}_{3}$-induced elevation of $\mathrm{Ca}_{\mathrm{i}}$ to the electrical response}

Positioning the laser beam at a stationary spot allowed detection of fluorescence with the highest temporal resolution as well as 

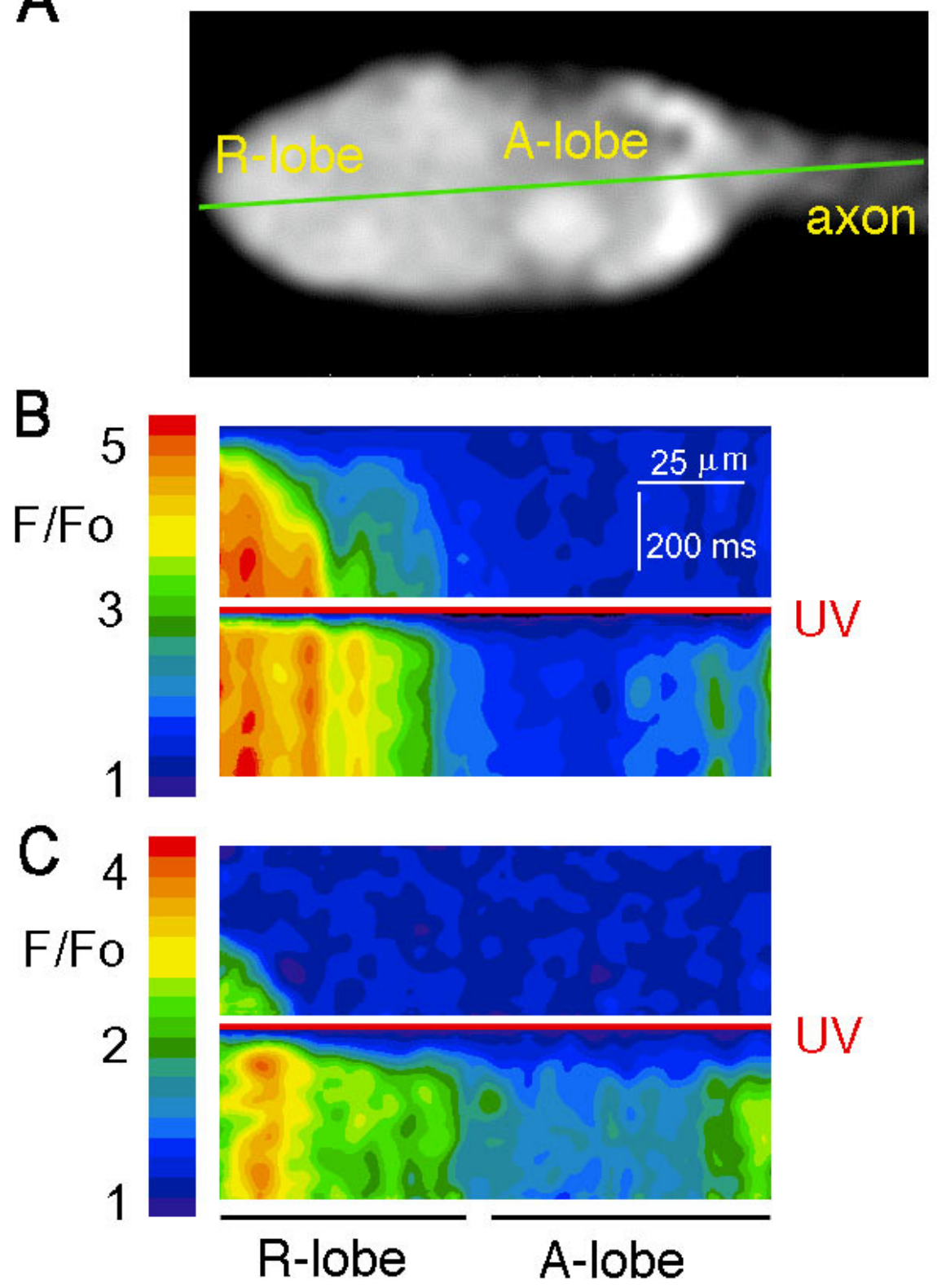

Figure 1. Photolysis of caged $\mathrm{InsP}_{3}$ initiates calcium release throughout Limulus ventral photoreceptors. $A$, Ventral photoreceptor loaded with $10 \mathrm{~mm}$ GDP- $\beta$ S, 1 $\mathrm{mm}$ Fluo-3, and $10 \mathrm{~mm}$ caged $\mathrm{InsP}_{3}$. The laser beam scanned along the green line every $4 \mathrm{msec}$, and the resulting lines of fluorescence data were stacked to create the images below. B, Upper frame, Fluorescence recorded during a line scan with a $488 \mathrm{~nm}$ laser beam, which excited the photoreceptor through the physiological mechanism. The scan shows the temporal progression of the physiological elevation of $\mathrm{Ca}_{\mathrm{i}}$ from the edge of the R-lobe membrane (left-hand edge of scan) into the A-lobe (right-hand side of scan). The laser beam started scanning across the cell at a time indicated by the first line of the image. The left-hand side of each scanned line was cropped to eliminate pixels beyond the edge of the R-lobe (determined as the point at which total fluorescence drops by $50 \%$ ). The right-hand edge of each scanned line also was cropped to eliminate the final 100 pixels in which laser illumination was not uniform (see Materials and Methods). $B$, Lower frame, A $10 \mathrm{msec}$ flash from a UV (351/364 $\mathrm{nm}$ ) laser, relative intensity 0.5 (red line), was superimposed at the beginning of the scan. The resulting photolysis of caged Ins $\mathrm{P}_{3}$ induced fast calcium release throughout the cell. $C$, To exclude any contribution of $\mathrm{Ca}^{2+}$ influx, we kept a different cell in darkness for 30 min in ASW containing $1 \mathrm{~mm}$ EGTA instead of $10 \mathrm{~mm}$ $\mathrm{Ca}^{2+}$. This increased the latency of response to the 488 $\mathrm{nm}$ laser via the physiological mechanism (upper frame) but did not alter the latency or pattern of elevation of $\mathrm{Ca}_{\mathrm{i}}$ after photolysis of $\mathrm{InsP}_{3}$ (lower frame). microphotolysis at the fastest rate. The spot chosen was located at the edge of the R-lobe where the fastest elevations of calcium via the physiological mechanism were observed. Because this placement was based on the spatially smoothed line scan images of calcium release, resolution of the edge of R-lobe was limited to $\sim 4 \mu \mathrm{m}$ (see Materials and Methods). During a $488 \mathrm{~nm}$ flash delivered to this spot, calcium release via the physiological mechanism began after a latent period of $42 \mathrm{msec}$ and rapidly saturated the Fluo-3 (Fig. 2A). Membrane depolarization was detected simultaneously with the calcium release. A brief superimposed UV flash, which photolyzed caged $\mathrm{InsP}_{3}$, initiated calcium release with a greatly reduced latency of $13 \mathrm{msec}$ (Fig. 2B). Membrane depolarization followed $2 \mathrm{msec}$ later. We attribute this earlier calcium elevation and electrical response to photolytic release of $\mathrm{InsP}_{3}$ by the UV flash.

The low-affinity calcium indicator dye Calcium Green-5N (Haugland, 1992) was used to better compare peak elevations of
$\mathrm{Ca}_{\mathrm{i}}$. Calcium Green-5N saturates at much higher levels of $\mathrm{Ca}_{\mathrm{i}}$ than Fluo-3 and is therefore more suitable for following the time course and magnitude of large elevations of $\mathrm{Ca}_{\mathrm{i}}$. The $488 \mathrm{~nm}$ laser again was focused onto a spot at the edge of the R-lobe. Calcium Green-5N fluorescence during a $488 \mathrm{~nm}$ step rose similarly to the Fluo-3 signals (Fig. 2C), reaching a peak within $\sim 100 \mathrm{msec}$. Photolysis of caged $\mathrm{InsP}_{3}$ at the same spot induced a peak fluorescence increase that was nearly threefold larger than that activated by $488 \mathrm{~nm}$ light alone (Fig. 2D) and reached its peak within $20 \mathrm{msec}$, implying an extremely fast and large $\mathrm{Ca}_{\mathrm{i}}$ rise.

We investigated the effect of removing extracellular $\mathrm{Ca}^{2+}$ and of voltage-clamping photoreceptors. Figure 3 shows inward current and fluorescence recorded from a voltage-clamped photoreceptor that had been filled with Fluo-3, GDP- $\beta$ S, and caged InsP $P_{3}$. Before stimulating the cell, the photoreceptor was bathed in darkness for $30 \mathrm{~min}$ in ASW containing $1 \mathrm{~mm}$ EGTA instead of 10 $\mathrm{mm} \mathrm{CaCl}_{2}$. As expected from the line scans (Fig. 1C), the latent 
Fluo-3

A

Figure 2. Timing of calcium release by using the stationary spot mode of the laser. Photoreceptors were loaded with either Fluo-3 or Calcium Green-5N, caged $\mathrm{InsP}_{3}$, and GDP- $\beta \mathrm{S}$. The $488 \mathrm{~nm}$ and UV (351/364 $\mathrm{nm})$ laser beams were focused onto the edge of the R-lobe, equivalent to the extreme left-hand edge of the photoreceptor in Figure $1 A$. $A$, Membrane potential (solid line) and Fluo-3 fluorescence (dots) recorded during illumination by the $488 \mathrm{~nm}$ laser. Laser stimulation started at the beginning of the fluorescence trace. $B$, Effect of superimposing a $20 \mathrm{msec}$ duration UV flash. $C$, Membrane potential and Calcium Green-5N fluorescence recorded from a photoreceptor illuminated by the $488 \mathrm{~nm}$ laser. $D$, Effect of superimposing a 3-msec-duration UV flash. The rapid reduction in fluorescence in $B$ and $D$ on termination of the UV flash is attributable to cessation of autofluorescence and additional Fluo-3 fluorescence created by the UV illumination; relative intensity 0.05 in $B$ and 0.5 in $D$. Fluorescence was sampled every $0.9 \mathrm{msec}$ in $A$ and $C$ and every 0.2 msec in $B$ and $D$.

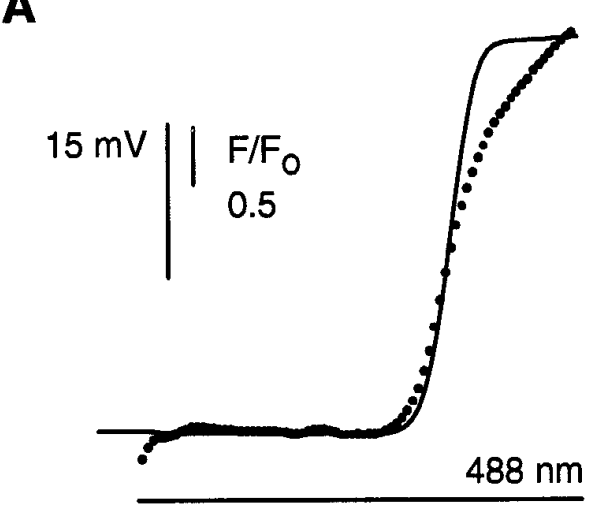

B

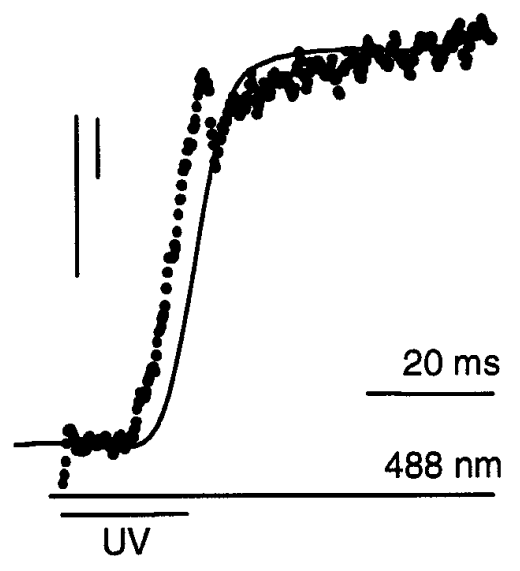

CaGreen5N

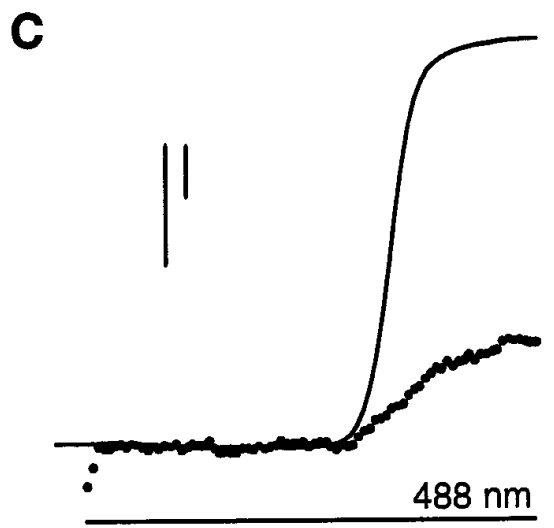

D

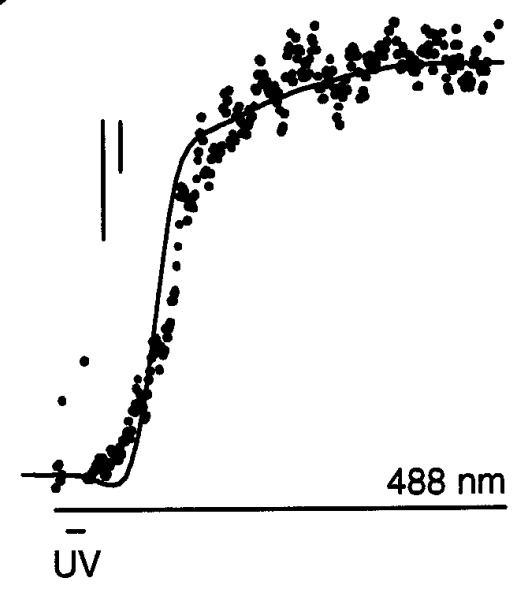

period of the response to the $488 \mathrm{~nm}$ flash alone (Fig. $3 A$ ), but not to the superimposed UV flash (Fig. $3 B$ ), was greatly prolonged, as compared with control conditions (compare Figs. 2 and 3, noting the different time scales). The relationship between the timing of the electrical response and the fluorescence traces that followed photolysis of caged $\mathrm{InsP}_{3}$ by the UV flash was also similar to that seen under control conditions (Fig. 3, inset). Removal of extracellular calcium for many minutes therefore did not greatly affect the coupling of $\mathrm{InsP}_{3}$-induced calcium release to the generation of inward current.

For further analysis of the data obtained in normal ASW, we compared the latency of the electrical response and of the $\mathrm{Ca}_{\mathrm{i}}$ elevation induced by the photolysis of caged $\mathrm{InsP}_{3}$ at the edge of the R-lobe. The complete data are plotted as a scatter diagram in Figure 4 (solid circles). The mean latency of the calcium signals (the first detectable increase in Fluo-3 fluorescence) that followed photolysis of caged $\mathrm{InsP}_{3}$ by the UV flash was $17 \pm 6 \mathrm{msec}$ (mean $\pm \mathrm{SD} ; n=42 ; 14$ cells), whereas the mean latency of the electrical response was $20 \pm 6 \mathrm{msec}$. The variable latency of the $\mathrm{InsP}_{3}$-induced calcium signal may be a general property of $\mathrm{InsP}_{3}$ induced calcium release, shared with other cells (Parker and Ivorra, 1993). However, the relative timing of the calcium signal and the electrical response exhibited less variability. On average, the $\mathrm{InsP}_{3}$-induced calcium signal led the electrical response by $2.5 \pm 3.3$ msec.

Latencies for the responses to physiological stimulation of the cell by $488 \mathrm{~nm}$ illumination alone were longer than those for the responses to the release of caged $\mathrm{InsP}_{3}$ (Fig. 4, open circles). The mean latency of the physiological electrical response was $45 \pm 12 \mathrm{msec}(n=52 ; 14$ cells $)$, whereas the latency of the accompanying calcium signals was $48 \pm 12 \mathrm{msec}$. The comparatively large SD of these data reflect, in part, the known variability inherent in the process that determines the latency of the physiological response to individual quanta (Yeandle and Spiegler, 1973) including, presumably, the time taken to generate $\mathrm{InsP}_{3}$ and for $\mathrm{InsP}_{3}$ to release calcium (see above). The distribution of the latencies also differed from those elicited after photolysis of caged $\mathrm{InsP}_{3}$. The majority (32 of 52) of the latency data for the physiological responses falls above the diagonal line in Figure 4, indicating that the detection of calcium release often slightly lagged the initiation of the physiological electrical response. One explanation for the difference in the distributions of latencies might be the time taken for calcium to diffuse small distances. Even at the highest diffusion rate of $227 \mu \mathrm{m}^{2} / \mathrm{sec}$ (Allbritton et al., 1992), $\mathrm{Ca}^{2+}$ ions will take $\sim 3 \mathrm{msec}$ to travel $1 \mu \mathrm{m}$. The resolution of the edge of the R-lobe, determined from line scan images of calcium release, was limited by spatial smoothing to $\sim 4 \mu \mathrm{m}$. Thus, the confocal spot could have been placed a few micrometers from the microvillar membrane of the R-lobe. This error in placement might account for the systematic difference in the timing of the physiological and $\mathrm{InsP}_{3}$-induced calcium signals. Calcium released by the physiological mechanism would be expected to be initiated from calcium stores directly beneath the microvillar 


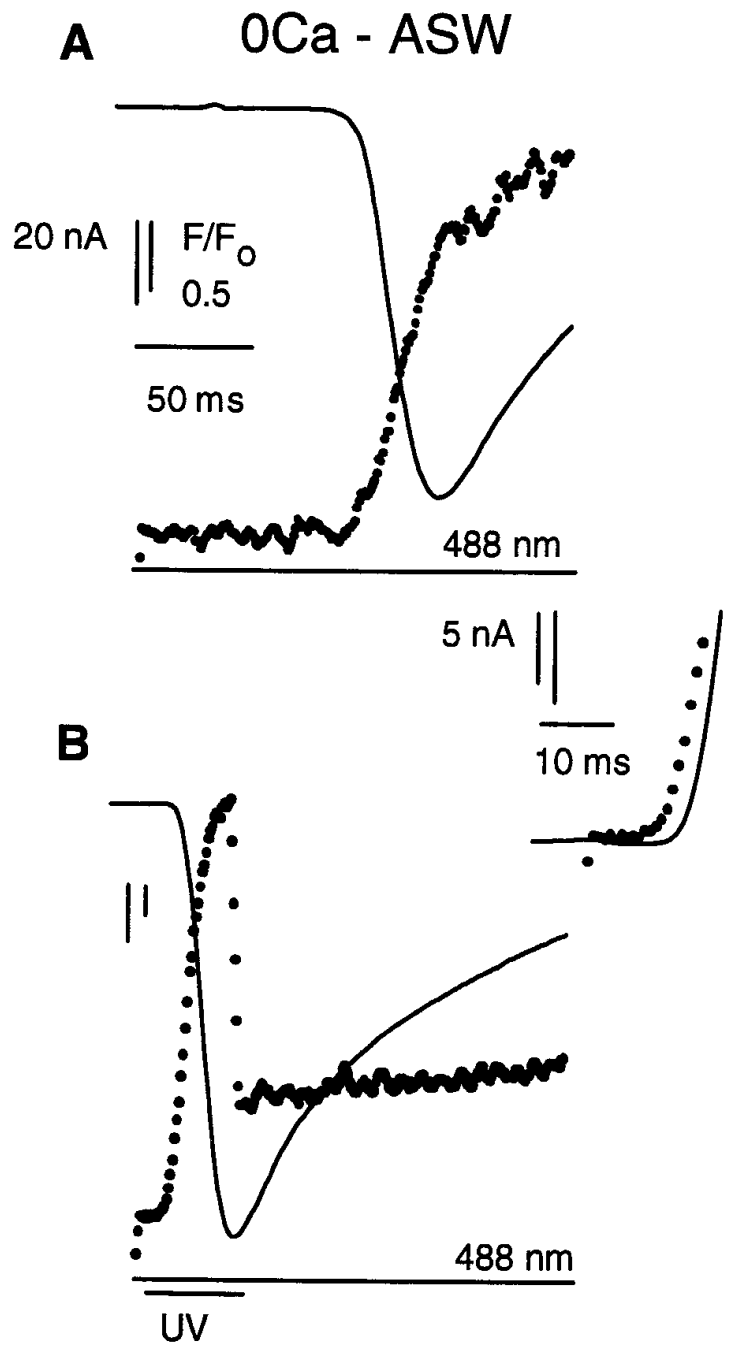

Figure 3. Removal of extracellular $\mathrm{Ca}^{2+}$ does not affect $\operatorname{InsP}_{3}$-induced calcium release in Limulus ventral photoreceptors. $A$, Membrane current (solid line) and Fluo-3 fluorescence (dots) recorded from a photoreceptor voltage-clamped to its resting membrane potential and illuminated by a $488 \mathrm{~nm}$ laser. The photoreceptor was bathed in artificial seawater containing $1 \mathrm{~mm}$ EGTA instead of $10 \mathrm{mM} \mathrm{Ca}^{2+}$. Note the change in time scale, as compared with Figure 2. $B$, Effect of superimposing a $40 \mathrm{msec}$ duration UV flash. The rapid reduction in fluorescence in $B$ on termination of the UV flash is attributable to cessation of autofluorescence and additional Fluo-3 fluorescence created by the UV illumination; relative intensity 0.5 . Fluorescence was sampled every $0.9 \mathrm{msec}$.

membrane, where light-induced production of $\mathrm{InsP}_{3}$ occurs. This physiological release of calcium immediately would open channels in the plasma membrane. However, if the confocal measuring spot were placed more than a micrometer from the microvillar membrane, the calcium ions would have to diffuse to the spot to be detected. The detection of the calcium signal would, therefore, be expected to lag the physiological electrical response by a few milliseconds. On the other hand, calcium ions released by photolysis of caged $\mathrm{InsP}_{3}$ from stores at the same distant confocal spot would be detected immediately, but the calcium ions would have to diffuse to the microvillar membrane to initiate an electrical response. If the confocal measuring spot were placed more than a micrometer from the microvillar membrane, the calcium signal might, therefore, be expected to lead the electrical response to photolysis of caged
- control

- caged IP3

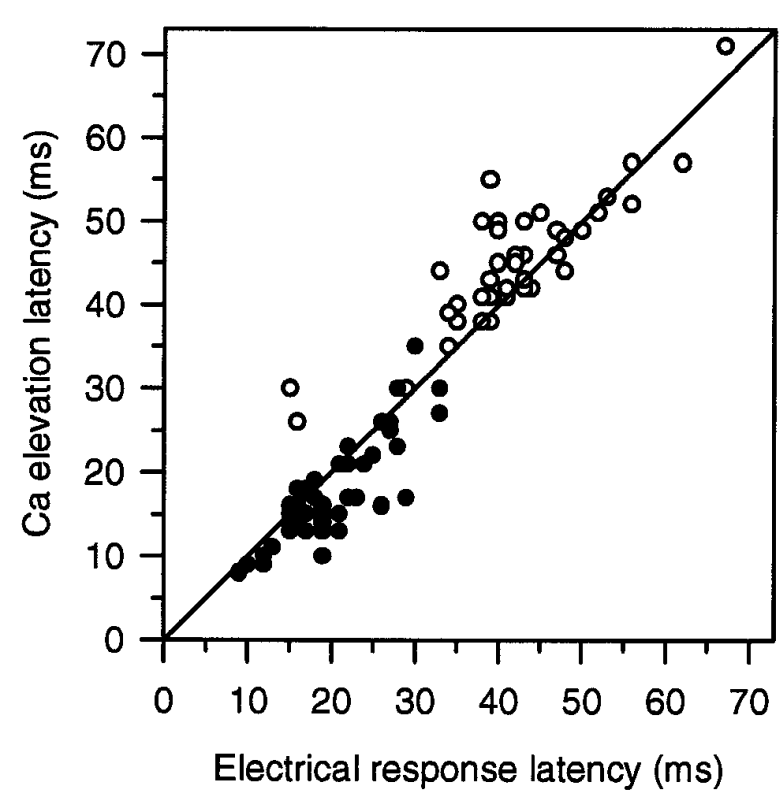

Figure 4. A scatter plot of the latencies of the calcium signal (both Fluo-3 and Calcium Green-5N fluorescence) and of the electrical responses (either photocurrent or changes in membrane potential) after photolysis of caged InsP $\mathrm{P}_{3}$ ( filled circles) or during the physiological response to 488 $\mathrm{nm}$ light (open circles). A straight diagonal line indicating equality of the two latencies is drawn to show the slightly different distributions of the two sets of data points.

InsP $_{3}$ by a few milliseconds but to lag the physiological electrical response to $488 \mathrm{~nm}$ light.

\section{Photolysis of caged ATP had little effect on calcium release or the electrical response}

We were concerned that the absorption of UV light by rhodopsin, in addition to the release of caged $\mathrm{InsP}_{3}$, might accelerate the response of the cell when the UV flash was superimposed on the $488 \mathrm{~nm}$ step. We therefore substituted caged ATP for caged $\mathrm{InsP}_{3}$ in the solution injected into the cells and repeated some of the above experiments. Responses from cells coinjected with $10 \mathrm{~mm}$ caged ATP, Fluo-3, and GDP- $\beta$ S did not exhibit a large reduction in the latency of their response when the UV flash was superimposed on the $488 \mathrm{~nm}$ flash (Fig. 5). The mean latencies of the calcium signals after the $488 \mathrm{~nm}$ laser flash were $42 \pm 2 \mathrm{msec}$ without the UV flash and $39 \pm 5 \mathrm{msec}(n=8)$ with the superimposed UV flash (relative intensity 0.5 , duration $30 \mathrm{msec}$ ), whereas those of the electrical responses were $37 \pm 5$ and $33 \pm 7 \mathrm{msec}$, respectively. We presume that the UV flash is relatively ineffective because the $488 \mathrm{~nm}$ illumination alone locally saturates the physiological response to light. The UV flash, however, does elicit increased autofluorescence and Fluo-3 fluorescence (Fig. 5B). Because the UV flash, by itself, does not significantly alter the initial response of the cell to the $488 \mathrm{~nm}$ light, we attribute the effects of UV stimulation of cells loaded with caged compounds to the release of active $\mathrm{InsP}_{3}$ or free $\mathrm{Ca}^{2+}$.

\section{Use of caged calcium}

To determine the speed of action of released $\mathrm{Ca}$ independently, we directly released calcium from NPE. Injection of photorecep- 
A caged ATP

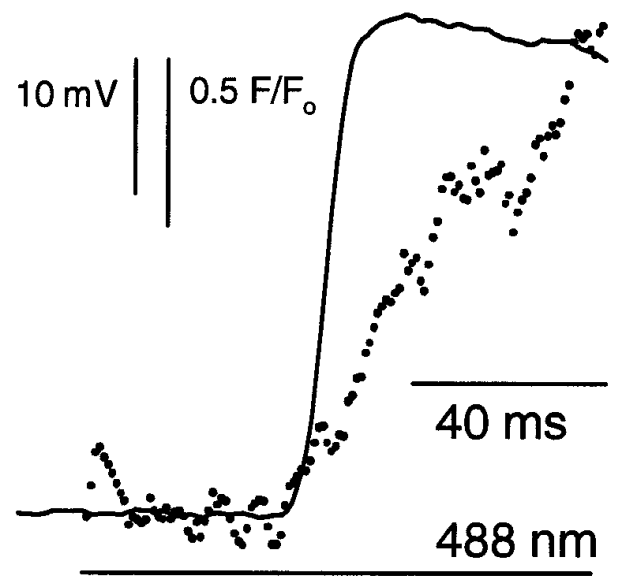

B

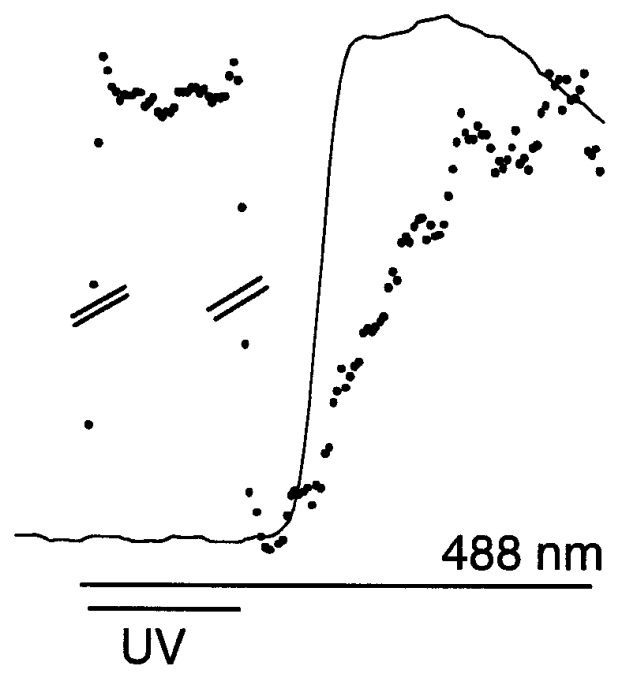

Figure 5. Photolysis of caged ATP does not alter either electrical excitation or light-induced calcium release in Limulus ventral photoreceptors. Photoreceptors were loaded with Fluo-3, caged ATP, and GDP- $\beta$ S. The $488 \mathrm{~nm}$ and UV (351/364 nm) laser beams were focused onto the edge of the R-lobe, equivalent to the extreme left-hand edge of the photoreceptor in Figure 1A. A, Membrane potential (solid line) and Fluo-3 fluorescence (dots) recorded during illumination by a $488 \mathrm{~nm}$ laser. Laser stimulation began at the beginning of the fluorescence trace. $B$, Effect of superimposing a $30 \mathrm{msec}$ UV flash; relative intensity 0.5 . The break in the vertical scale represents $7.5 \mathrm{~F} / \mathrm{F}_{\mathrm{o}}$ units and is needed to show the time course of autofluorescence excited by the UV light.

tors with $40 \mathrm{~mm} 0.8 \mathrm{Ca}-\mathrm{NPE}$ decreased the latent period of the physiological response to $488 \mathrm{~nm}$ light to $<30 \mathrm{msec}$ (compare Fig. $6 B$ ). This effect can be ascribed to the higher $\mathrm{Ca}_{\mathrm{i}}, 1 \mu \mathrm{M}$, in the injection solution, as compared with the normal resting $\mathrm{Ca}_{\mathrm{i}}$ of 0.4 $\mu \mathrm{M}$, because calcium elevation is known to reduce response latency (Fein and Charlton, 1977). NPE injection also slowed the rise time of the fluorescence increase caused by calcium released via the physiological mechanism [compare the fluorescence trace in Fig. $2 A$ with the control $(U V=0)$ trace in Fig. $6 A]$. We ascribe this to the buffering of $\mathrm{Ca}_{\mathrm{i}}$ by NPE. Photolytic release of $\mathrm{Ca}^{2+}$ ions in the vicinity of the photoreceptor membrane by a $3 \mathrm{msec}$ UV flash induced an inward current that clearly consisted of more than one component (traces labeled $U V=1.0, U V=2.5$ in Fig.
$6 B)$. An early transient inward current, rising to peak within 10 msec, was observed only after the UV flash and was attributed to the photolysis of NPE. The physiological response to the $488 \mathrm{~nm}$ light would not be expected to exhibit such an early transient current because of the 30-60 msec latent period associated with the physiological release of calcium (traces labeled $U V=0$ in Fig. 6). A later larger current component induced by the UV flash rose at approximately the same time as the response to the $488 \mathrm{~nm}$ step and was, therefore, attributed to the physiological response. To verify that most of this early ionic current flows via ion channels rather than via the activation of an electrogenic $\mathrm{Na} / \mathrm{Ca}$ exchanger, we determined its reversal potential under voltage clamp. Reversal of the early NPE-induced current is shown in Figure $6 C$. The reversal potential $\left(E_{\text {rev }}\right)$ lay between 3 and $22 \mathrm{mV}$, averaging $10 \pm$ $6 \mathrm{mV}(n=4)$. The bulk of the current that followed the early NPE-induced transient reversed at a slightly more positive potential in all cells, averaging $19 \pm 6 \mathrm{mV}$. In separate experiments, reversal of the inward current activated by the photolysis of caged $\mathrm{InsP}_{3}$ also was observed (data not shown). At high intensities of the UV laser, the latency of the electrical response to photolysis of caged NPE followed the onset of the UV flash by $1.8 \pm 0.7 \mathrm{msec}$ (mean $\pm \mathrm{SD}, 5$ cells). There is, therefore, a good agreement with the $2.5 \pm 3.3 \mathrm{msec}$ delay of the electrical response with respect to the calcium signal after photolysis of caged $\mathrm{InsP}_{3}$.

\section{DISCUSSION}

Faddis and Brown (1992) investigated the electrical response of ventral photoreceptors after flash photolysis of $\mathrm{InsP}_{3}$ produced by diffuse illumination. They observed that release of caged $\mathrm{InsP}_{3}$ increased the peak current produced through the physiological mechanism via the activation of rhodopsin. However, they could not separate the $\mathrm{InsP}_{3}$-induced current from the physiological light-induced current. Our confocal method reduces overall illumination of the photoreceptor while concentrating the UV light. This technique reduces the overall stimulation of the cell via the physiological mechanism while maximizing the concentration of $\mathrm{InsP}_{3}$ released at its site of action. As a result, we were able to observe an electrical response to the release of caged $\operatorname{InsP}_{3}$ during the latent period when no physiological response to light is detectable. Our results confirm their main conclusion-that the 10-20 msec delay between photolysis of $\mathrm{InsP}_{3}$ and the electrical response indicates that the latter is not caused by the direct rapid interaction of $\mathrm{InsP}_{3}$ with a channel in the microvillar membrane. Rather, our simultaneous measurements of $\mathrm{Ca}_{\mathrm{i}}$ indicate that the electrical response immediately follows and is caused by the release of $\mathrm{Ca}^{2+}$ ions (Payne et al., 1986).

\section{Location of Ins $\mathrm{P}_{3}$-sensitive calcium stores}

Photolysis of caged $\mathrm{InsP}_{3}$ released calcium from stores within both the lobes of Limulus ventral photoreceptors. We note that not all of the calcium release necessarily passes through $\mathrm{InsP}_{3}$-gated channels in the endoplasmic reticulum. Some might be the consequence of a secondary wave of calcium-induced calcium release. The consequent elevation of $\mathrm{Ca}_{\mathrm{i}}$ is larger in the R-lobe than in most regions of the A-lobe, with the exception of an area close to the axon. Earlier experiments using aequorin as a calcium indicator failed to reveal any significant calcium release on microinjection of $\mathrm{InsP}_{3}$ into the A-lobe (Payne and Fein, 1986). More sensitive calcium-selective microelectrode recordings, however, detected a relatively slow and small $(\sim 2 \mu \mathrm{M}) \mathrm{Ca}^{2+}$ transient after injection of $100 \mu \mathrm{M} \mathrm{InsP}{ }_{3}$ into the A-lobe (Levy and Payne, 1993). Our results support the latter observations and suggest that the 


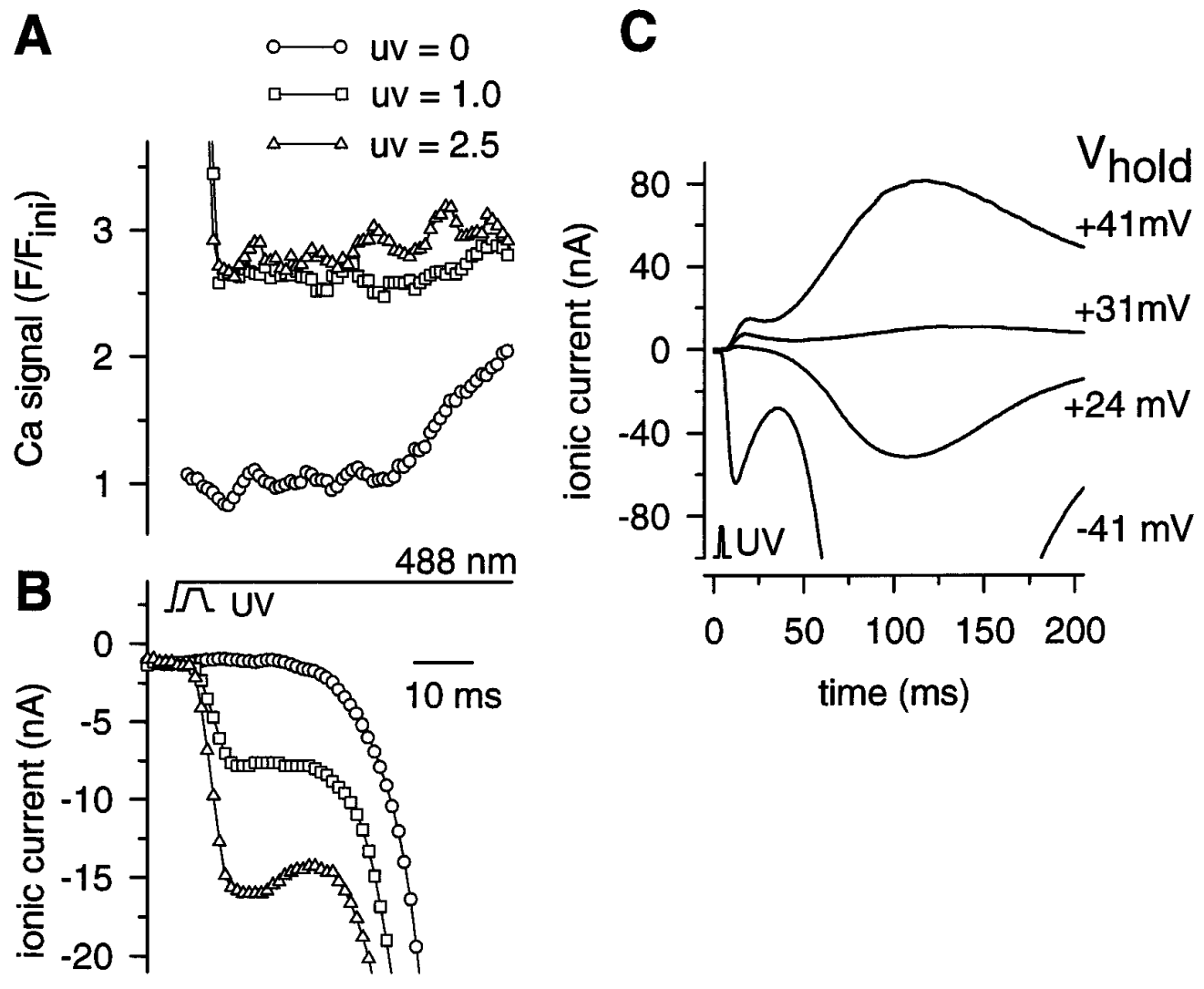

Figure 6. UV flashes activated an early inward ionic current in Limulus ventral photoreceptors loaded with 40 mM 0.8 Ca-NPE, Fluo-3, and GDP- $\beta$ S. A $3 \mathrm{msec}$ flash from a UV $(351 / 364 \mathrm{~nm})$ laser was superimposed on a $488 \mathrm{~nm}$ laser step. The relative intensity of the UV laser is as indicated in $A$. Both lasers were focused on a spot at the edge of the R-lobe of a ventral photoreceptor. $A$, Fluo-3 fluorescence, plotted as the ratio of the Fluo-3 fluorescence, $F$, observed during the response to that, $F_{\text {ini }}$, sampled before the onset of the first $\mathrm{UV}$ flash in the series delivered to the cell. The detection of the elevation of $\mathrm{Ca}_{\mathrm{i}}$ induced via the normal physiological mechanism by the $488 \mathrm{~nm}$ laser alone $(U V=0)$ was slowed significantly as a result of the loading of the photoreceptor with NPE. The control trace $(U V=0)$ was recorded after the presentation of the UV flashes. $B$, Inward current activated within the 3 msec duration of the UV flashes. $C$, Reversal of inward ionic current generated in another cell loaded with NPE and GDP- $\beta S$ and illuminated by a 3 msec UV laser flash; relative intensity 50 . For this cell, $E_{\text {rev }}$ of the early current transient was estimated as $+22 \mathrm{mV}$.

aequorin imaging system was not sufficiently sensitive to detect release in the A-lobe. Our results are also consistent with a recent anatomical study showing that smooth endoplasmic reticulum (SER) is not confined to the submicrovillar region but that it forms a dense continuous network that extends from beneath the microvillar membrane into the center of the R-lobe. A less dense tubular reticulum, continuous with SER in the R-lobe, extends into the A-lobe (Feng et al., 1994). The $488 \mathrm{~nm}$ light would result in $\mathrm{InsP}_{3}$ production at the microvillar plasma membrane of the R-lobe through the PI pathway, creating a wave of calcium release from the SER that spreads into the center of the R-lobe and diminishes in magnitude as the $\mathrm{InsP}_{3}$ diffuses into the A-lobe. Release of caged $\mathrm{InsP}_{3}$, however, would elevate $\mathrm{Ca}_{\mathrm{i}}$ throughout the cell, with the magnitude of the elevation of $\mathrm{Ca}_{\mathrm{i}}$ in different cell regions being graded according to the density of the SER. This might explain the larger elevation of $\mathrm{Ca}_{\mathrm{i}}$ in the R-lobe, as compared with the bulk of the A-lobe.

The prominent $\mathrm{InsP}_{3}$-induced calcium release in the region of the A-lobe where the axon originates suggests another concentration of SER there. We know of no published study on the distribution of SER in this particular region of Limulus photoreceptors. However, the presence of prominent ER and of the $\mathrm{InsP}_{3}$ receptor protein in the axons of mammalian neurons has been well documented (Broadwell and Cataldo, 1984; Mignery et al., 1989). Because we do not detect any elevation of calcium concen- tration in the axon during the first second of the physiological response to light (Fig. $1 B$ ), we assume that the calcium stores in the axon are not involved in the immediate transmission of the light response along the axon. However, it may be that, during more prolonged illumination, $\mathrm{InsP}_{3}$ produced in the cell body may diffuse down the axon and regulate axonal function or structure. Alternatively, the calcium stores in the axon may be vesicles that are being transported to fulfill a role in the function of the axon terminal.

\section{Speed of coupling of calcium release to depolarization}

If, as is indicated by experiments on excised patches (Bacigalupo et al., 1991), calcium does not bind directly to and open ion channels in the microvillar membrane, then the intermediate steps that couple calcium to the activation of ion channels impose a delay of only 1-3 msec. The significance of this result for visual excitation depends on when calcium is released during the light response. Analysis of the control responses to $488 \mathrm{~nm}$ illumination (Fig. 4, open circles) indicates that the mean latency of the physiological electrical response was $45 \pm 12 \mathrm{msec}$, whereas the elevation of $\mathrm{Ca}_{\mathrm{i}}$ was first detected after $48 \pm 12 \mathrm{msec}$. Because it then takes $\sim 50 \mathrm{msec}$ for the photocurrent to reach its peak, there seems to be sufficient time for released calcium ions to contribute to the activation of the photocurrent during the rising edge of the response to light. This assertion is consistent with the large atten- 
uation of the rate of rise of the photocurrent produced by the intracellular injection of calcium chelators such as EGTA (Payne and Fein, 1986) and di-Bromo-BAPTA (Shin et al., 1993). However, because the detection of the physiological calcium signals often lagged that of the electrical response by a few milliseconds, we cannot assert that calcium elevation is the sole initiator of the electrical response. As noted in Results, a simple explanation for this lag is the time taken for the diffusion of calcium into the confocal spot after its release from SER immediately below the microvillar membrane. However, it is also possible that a parallel pathway of visual excitation exists, one which can initiate an electrical response but which does not require calcium release (Frank and Fein, 1991; Contzen et al., 1995). The possibility of such a pathway is discussed further below.

\section{Reversal potential of the calcium-activated current}

Previous experiments in which calcium was pressure-injected into the R-lobe concluded that both the calcium-induced current and the light-induced current reversed between +10 and $+20 \mathrm{mV}$ (Payne et al., 1986). The present experiments confirm this approximate range for the reversal potentials but indicate a consistent difference between the reversal potentials of current components activated by photolysis of caged calcium and by the physiological mechanism in the presence of NPE. The early transient, ascribed to calcium release, reversed at $10 \pm 6 \mathrm{mV}$, whereas the much larger later component, ascribed to the physiological mechanism, reversed at $19 \pm 6 \mathrm{mV}$. This difference in $E_{\mathrm{rev}}$ may be significant. The response of dark-adapted ventral photoreceptors to bright light flashes does not reverse at a unique potential and has been interpreted as consisting of three components, each having a $E_{\mathrm{rev}}$ differing by a few millivolts (Deckert et al., 1992). The second of these components, $\mathrm{C}_{2}$, reverses at a potential a few millivolts below that of the other components. Pharmacological experiments (Nagy, 1991; Contzen and Nagy, 1995) have suggested that the $\mathrm{C}_{2}$ is mediated via Ins $_{3}$-induced calcium release, whereas the other components possibly are mediated via cyclic nucleotide metabolism. If multiple pathways of excitation exist, then under the conditions of our flash photolysis experiment we would expect the buffering of calcium by NPE to reduce the contribution of calcium release to the physiological response relative to other mechanisms. According to the proposal of Nagy and collaborators, the early calcium-activated component of the response to the photolysis flash may, therefore, be expected to display a more negative reversal potential than the later physiological response.

Nagy and collaborators ascribe the different components of the light response to the activation of different channels by the various messenger pathways (Deckert et al., 1992). We think it is unlikely that further analysis of small differences in reversal potential will yield a definitive answer as to whether more than one channel mediates the light response. A very large increase in $\mathrm{Ca}_{\mathrm{i}}$ accompanies the light response (Ukhanov and Payne, 1995), and the light-activated channels may be calcium-permeable, or the voltage-gated channels that mediate the current induced by depolarizing voltage steps may be calcium-sensitive. These factors may distort the waveform of the photocurrent close to the reversal potential (O'Day et al., 1993). A future combination of local flash photolysis of NPE with patch-clamp recording, however, may allow the direct comparison of single channels activated by released calcium and by the physiological mechanism under different conditions.

\section{Comparison with Drosophila photoreceptors}

It is noteworthy that experiments recently performed on Drosophila photoreceptors with similar methods have failed to observe any ionic current directly activated by the photolysis of caged calcium. Flash photolysis of DM-Nitrophen loaded by dialysis into dissociated Drosophila photoreceptors activates only the $\mathrm{Na} / \mathrm{Ca}$ exchanger (Hardie, 1996). Instead, a physical link has been proposed between the activation of the $\mathrm{InsP}_{3}$ receptor and the opening of the putative channel protein TRP (Hardie and Minke, 1995). This difference may indicate that microvillar photoreceptors of invertebrates have evolved a variety of linkages of the PI pathway to ion channel activation.

\section{REFERENCES}

Allbritton NL, Meyer T, Stryer L (1992) Range of messenger action of calcium ion and inositol 1,4,5 trisphosphate. Science 258:1812-1815.

Bacigalupo J, Johnson EC, Vergara C, Lisman JE (1991) Lightdependent channels in excised patches of Limulus ventral photoreceptors are opened by cyclic GMP. Proc Natl Acad Sci USA 88:7938-7942.

Berridge MJ (1993) Inositol trisphosphate and calcium signalling. Nature 361:315-325.

Bloomquist BT, Shortridge RD, Schneuwly S, Pedrew M, Montell C, Steller H, Rubin G, Pak WL (1988) Isolation of a putative phospholipase $\mathrm{C}$ gene of Drosophila norpA and its role in phototransduction. Cell 54:723-733.

Broadwell RD, Cataldo AM (1984) The neuronal endoplasmic reticulum: its cytochemistry and contribution to the endomembrane system. II. Axons and terminals. J Comp Neurol 230:231-248.

Brown JE, Rubin LJ, Ghalayini AJ, Tarver AL, Irvine RF, Berridge MJ, Anderson RE (1984) myo-Inositol polyphosphate may be a messenger for visual excitation in Limulus photoreceptors. Nature 311:160-162.

Calman BS, Chamberlain S (1982) Distinct lobes of Limulus photoreceptors. II. Structure and ultrastructure. J Gen Physiol 80:839-862.

Contzen K, Nagy K (1995) Current components stimulated by different G-proteins in Limulus ventral photoreceptor. NeuroReport 6:1905-1908.

Contzen K, Richter K-H, Nagy K (1995) Selective inhibition of the phospholipase $\mathrm{C}$ pathway blocks one light-activated current component in Limulus photoreceptor. J Comp Physiol 177:601-610.

Deckert A, Nagy K, Helrich CS, Stieve H (1992) Three components in the light-induced current of the Limulus ventral photoreceptors. J Physiol (Lond) 453:69-96.

Ellis-Davies GCR, Kaplan JH (1994) Nitrophenyl EGTA, a photolabile chelator that selectively binds $\mathrm{Ca}^{2+}$ with high affinity and releases it rapidly upon photolysis. Proc Natl Acad Sci USA 91:187-191.

Faddis MN, Brown JE (1992) Flash photolysis of caged compounds in Limulus ventral photoreceptors. J Gen Physiol 100:547-570.

Fein A (1986) Blockade of visual excitation in Limulus photoreceptor by GDP- $\beta$ S. Science 232:1543-1545.

Fein A, Charlton JS (1977) Enhancement and phototransduction in the ventral eye of Limulus. J Gen Physiol 69:553-569.

Fein A, Payne R, Corson DW, Berridge MJ, Irvine RF (1984) Photoreceptor excitation and adaptation by inositol 1,4,5 trisphosphate. Nature 311:157-160.

Feng J, Carson JH, Morgan F, Walz B, Fein A (1994) Three-dimensional organization of endoplasmic reticulum in the ventral photoreceptors of Limulus. J Comp Neurol 341:172-183.

Frank TM, Fein A (1991) The role of inositol phosphate cascade in visual excitation of invertebrate microvillar photoreceptors. J Gen Physiol 97:697-723.

Hardie RC (1996) INDO-1 measurements of absolute resting and lightinduced $\mathrm{Ca}^{2+}$ concentration in Drosophila photoreceptors. J Neurosci 16:2924-2933.

Hardie RC, Minke B (1995) Phosphoinositide-mediated phototransduction in Drosophila photoreceptors: the role of $\mathrm{Ca}^{2+}$ and trp. Cell Calcium 18:256-274.

Haugland RP (1992) Handbook of fluorescent probes and research chemicals, 5th Ed. Eugene, OR: Molecular Probes.

Hubbard R, Wald G (1960) Visual pigment of the horseshoe crab, Limulus polyphemus. Nature 186:212-215.

Levy S, Fein A (1985) Relationship between light-sensitivity and intra- 
cellular free calcium in Limulus ventral photoreceptors. J Gen Physiol 85:805-841.

Levy S, Payne R (1993) A lingering elevation of $\mathrm{Ca}_{\mathrm{i}}$ accompanies inhibition of inositol 1,4,5 trisphosphate-induced $\mathrm{Ca}$ release in Limulus ventral photoreceptors. J Gen Physiol 101:67-84.

Lisman JE (1976) Effects of removing extracellular $\mathrm{Ca}^{2+}$ on excitation and adaptation in Limulus ventral photoreceptors. Biophys J 16:1331-1335.

Mignery GA, Suedhoff TC, Takei K, De Camilli P (1989) Putative receptor for inositol 1,4,5 trisphosphate similar to ryanodine receptor. Nature 342:192-195.

Millecchia R, Mauro A (1969) The ventral photoreceptor cells of Limulus. III. A voltage-clamp study. J Gen Physiol 54:331-351.

Mitchell J, Gutierrez J, Northup JK (1995) Purification, characterization, and partial amino acid sequence of a G-protein-activated phospholipase C from squid photoreceptors. J Biol Chem 270:854-859.

Nagy K (1991) Biophysical processes in invertebrate photoreceptors: recent progress and a critical overview based on Limulus photoreceptors. Q Rev Biophys 24:165-226.

O'Day PM, Johnson EC, Freeman S (1993) A single class of lightactivated channel can yield biphasic light-induced currents at $\mathrm{E}_{\mathrm{rev}}$. Biophys J 64:A134.

Parker I, Ivorra I (1993) Confocal microfluorimetry of $\mathrm{Ca}^{2+}$ signals evoked in Xenopus oocytes by photoreleased inositol trisphosphate. J Physiol (Lond) 461:133-165.

Payne R, Fein A (1986) The initial response of Limulus ventral photoreceptors to bright flashes: released calcium as a synergist to excitation. J Gen Physiol 87:243-269.

Payne R, Flores TM (1992) The latency of the response of Limulus photoreceptors to inositol trisphosphate lacks the calcium-sensitivity of that to light. J Comp Physiol [A] 170:311-316.
Payne R, Ukhanov K (1996) Latencies of calcium elevation and depolarization in Limulus ventral photoreceptors injected with GDP- $\beta$ S. J Photochem Photobiol [B] 35:91-95.

Payne R, Corson DW, Fein A (1986) Pressure injection of calcium both excites and adapts Limulus ventral photoreceptors. J Gen Physiol $88: 107-126$.

Rack M, Xhonneux-Cremers B, Schraermeyer U, Stieve H (1994) On the $\mathrm{Ca}^{2+}$ dependence of inositol-phospholipid-specific phospholipase $\mathrm{C}$ of microvillar photoreceptors from Sepia officinalis. Exp Eye Res 58:659-664.

Ranganathan R, Malicki DM, Zuker C (1995) Signal transduction in Drosophila photoreceptors. Annu Rev Neurosci 18:283-317.

Shin J, Richard EA, Lisman JE (1993) $\mathrm{Ca}^{2+}$ is an obligatory intermediate in the excitation cascade of Limulus photoreceptors. Neuron 11:845-855.

Ukhanov KY, Payne R (1995) Light-induced calcium release in Limulus ventral photoreceptors as revealed by laser confocal microscopy. Cell Calcium 18:301-313.

Ukhanov KY, Flores TM, Hsiao H-S, Mohapatra P, Pitts CH, Payne R (1995) Measurement of cytosolic $\mathrm{Ca}^{2+}$ concentration in Limulus ventral photoreceptors using fluorescent dyes. J Gen Physiol 105:95-116.

Walker JW, Feeney J, Trentham DR (1989) Photolabile precursors of inositol phosphates: preparation and properties of 1-(2nitrophenyl)ethyl esters of myo-inositol 1,4,5 trisphosphate. Biochemistry 28:3272-3280.

Wang SS-H, Augustine GJ (1996) Confocal imaging and local photolysis of caged compounds: dual probes of synaptic function. Neuron 15:755-760.

Yeandle S, Spiegler JB (1973) Light-evoked and spontaneous discrete waves in the ventral nerve photoreceptor of Limulus. J Gen Physiol 61:552-571. 